DOI:

10.1038/nrn1965

URLs

DEVELOPMENT

\section{The triple-action factor}

This
multi-talented
protein
performs
each step by
a different
mechanism.

The development of post-mitotic neurons from neural precursors involves three steps: cell cycle exit, cell migration and cell differentiation. The cyclin-dependent kinase inhibitor $\mathrm{p} 27^{\mathrm{kip} 1}$ is known to be involved in controlling cell cycle exit, but now a new study by Guillemot and colleagues shows that it also regulates both migration and differentiation. This multi-talented protein performs each step by a different mechanism.

In the cerebral cortex of p $27^{\text {kip } 1-}$ null mutant mice embryos, there is a marked decrease in neuronal production (due to fewer cells exiting the cell cycle). However, some neurons are produced, and Guillemot's team were interested in discovering what happens to them so that they could find out whether p2 $7^{\text {kipl } 1}$ might be involved in additional developmental tasks. They labelled and followed the fate of the newly born neurons and observed that proportionately fewer cells migrated to the cortical plate from their birth place in the ventricular zone and that fewer cells expressed $\mathrm{HuC} / \mathrm{D}$ protein, a marker of post-mitotic neurons. These results indicate that both migration and differentiation were impaired in the absence of $\mathrm{p} 27^{\mathrm{kip} 1}$. By overexpressing $\mathrm{p} 27^{\mathrm{kip} 1}$ in the mutant mice, both defects were rescued.

In $\mathrm{p} 27^{\mathrm{ck}}$ embryos, as in p $27^{\mathrm{kip} 1}$ null embryos, a decrease in neuronal production is observed ( $\mathrm{p} 27^{\mathrm{ck}}$ mice express a version of the $\mathrm{p} 27^{\mathrm{kip} 1}$ protein that fails to promote cell cycle exit). However, unlike p2 $7^{\text {kip } 1 \text {-null }}$ embryos, the neurons that are produced in p27 $7^{\mathrm{ck}}$ embryos migrate and differentiate normally. Furthermore, the overexpression of p27 $7^{\mathrm{ck}}$ in $\mathrm{p} 27^{\mathrm{kip} 1}$ knockdown embryos rescues both the migration and differentiation defects, suggesting that the regulation of these processes by $\mathrm{p} 27^{\mathrm{kip} 1}$ involves an independent mechanism from that involved in cell cycle regulation.

Guillemot and colleagues suspected that this new mechanism might involve neurogenin 2 (Ngn2), as it too has been shown to regulate neuronal differentiation and migration. However, when Ngn2 was overexpressed in p27 $7^{\text {kip1-knockdown }}$ mice the differentiation defect was rescued but the migration defect was not. Instead, the migration defect was found to be rescued by overexpression of a dominant-negative form of RhoA - inactivation of RhoA had previously been shown to be necessary for $\mathrm{p} 27^{\mathrm{kip} 1}$-induced fibroblast migration.

To complete the study, the authors went on to determine the different parts of the $\mathrm{p} 27^{\mathrm{kip} 1}$ protein responsible for its two newly discovered functions. Altogether, the work by Guillemot's group provides extensive insight into both the workings of this multi-talented protein and the mechanisms underlying neurogenesis.

Ruth Williams

ORIGINAL RESEARCH PAPER Nguyen, L. et al. $\mathrm{p} 27^{\mathrm{kip} 1} 1$ independently promotes neuronal differentiation and migration in the cerebral cortex. Genes Dev. 16 May 2006 (doi:10.1101/ gad.377106) 